\title{
Socio-demographic factors affecting knowledge level of Tuberculosis patients in Rajshahi City, Bangladesh
}

\author{
M N I Mondal ${ }^{1}$, Hoque M. Nazrul' 2 M R K Chowdhury ${ }^{1}$, J Howard ${ }^{3}$
}

1. Department of Population Science and Human Resource Development University of Rajshahi, Bangladesh

2. Hobby Center for Public Policy, University of Houston, Houston, Texas 77504, USA

3. Department of Demography University of Texas at San Antonio 501 West Cesar E. Chavez Blvd. San Antonio, Texas 78207-4415

\begin{abstract}
Background: The Tuberculosis (TB) control program in Bangladesh is still unsatisfactory due to insufficient knowledge and stigma about TB. Patients with low knowledge may be at higher risk of experiencing delays in diagnosis and appropriate treatment.

Objectives: The aims of this study were to identify the knowledge levels of TB and investigate the factors associated with knowledge level among the TB patients in Bangladesh.

Methods: A cross-sectional study was conducted at Rajshahi City, Bangladesh. A total of 384

TB patients were interviewed through a pretested, structured questionnaire using purposive sampling techniques.

Logistic regression analysis was used to evaluate the effects of selected socio-demographic factors on TB knowledge level.

Results: The results revealed that pulmonary TB patients had greater knowledge than that of extra-pulmonary patients, and that sex, age, educational status and TB type were significantly associated with knowledge level.

Conclusions: In general, males and young adults, ages 21-35, had greater awareness about transmission and prevention of TB than females and adults over 35. Individuals with higher education and urban area patients were comparatively better informed about TB infection. Patients with greater knowledge about TB were also less likely to experience delays in seeking treatment.
\end{abstract}

Key words: Tuberculosis, National TB program, Rajshahi City, Knowledge index, Logistic regression model.

DOI: http://dx.doi.org/10.4314/ahs.v14i4.13

\section{Introduction}

Tuberculosis (TB) is a chronic communicable bacterial disease that remains an important public health problem, especially in developing countries. TB is an airborne, infectious disease caused by bacteria which primarily affect the lungs. Approximately one third of the world's population carries the TB bacteria namely Mycobacterium TB (MTB). The World Health Organization (WHO) declared TB as a 'global emergence' in $1993^{1}$. Every year almost two million people die worldwide due to TB and most deaths occur in low- and middle-income countries ${ }^{2}$.

\section{Corresponding author: \\ Hoque M. Nazrul \\ Hobby Center for Public Policy \\ University of Houston \\ Houston, Texas 77504, USA \\ E-mail:mnhoque@uh.edu}

Although TB is a curable disease, it ranks as the second leading cause of death among infectious diseases worldwide, after the human immunodeficiency virus (HIV). TB takes advantage of individual's with weakened immune systems, which is why it is called an opportunistic infectious disease. Consequently, the risk of TB infection is higher among the people who are HIV positive ${ }^{3-5}$. Bangladesh has been ranked 6th among 22 high burden countries (HBCs) where, the incidence rate was 225 per 100,000 population and TB mortality rate was 43 per 100,000 population in $2010^{2}$. To fight against TB, the Bangladesh National TB Control Program(NTP) has adopted the directly observed treatment short course (DOTs) strategy since $1993^{6}$.

At present, Bangladesh has more than 165 million people, and is the seventh most populous country in the world. It is also one of the poorest nations, and faces great challenges in providing health care services including TB services for its citizens. People having symp- 
they seek care at a general health facility, and rferred to the specialized TB health care centers for diagnosis, treatment and case management. Given the challenges facing Bangladesh' health services infrastructure, this is often a difficul goal to achieve.

Early case detection depends on patients' perceptio about their needs of seeking healthcare. Consequently, it is very important to make people understand when and where they should seek healthcare. Health knowledge allows individuals to assess symptoms, identify causes and transmission routes, and provide familiarity with the availability of treatment and cure. Likewise, knowledge and awareness of $\mathrm{TB}$ is very importan among TB affected people. Increasing knowledge will lead to overcoming some of the challenges to control TB. While people may have a general idea of what TB is and how it is treated, gaps in knowledge, such as transmission, treatment, and prevention causes diagnostic and treatment delays among many people living with TB. Delays in treatment occur for several reasons, such as, lack of knowledge, lack of awareness of the significance of symptoms, negative social attitudes or different combinations of these three factors ${ }^{7}$. Patients with low knowledge about symptoms are less likely to seek healthcare and get diagnosed. Patients with low knowledge are more likely to visit traditional healers and pharmacists rather than DOTs providers, which leads to delays in diagnosis and appropriate treatment.

Although most deaths due to TB occurred among men, the burden of TB is high among women as well. In 2012, an estimated 410,000 women died from TB. In Bangladesh, women tend to have longer diagnostic and treatment delays compared to men ${ }^{8}$. Lack of TB knowledge has been shown to be associated with diagnostic delay and in some case it is associated with poverty ${ }^{9-12}$. Bangladesh is considered to be a low human development country based on the value of Human Development Index (HDI $=0.500)$, placed 146 out of 187 countries and territories ${ }^{13}$. Consequently, Bangladesh has no had much success in the areas of education and health Obviously, education is significantly associated with health and makes a great impact on the enhancement on people's knowledge about $\mathrm{TB}^{14}$. To-date, no stud has been published with a focus on knowledge level and socio-demographic factors among TB patients in $\mathrm{Ra}$ shahi City, Bangladesh. Therefore, the purposes of the study were to identify the knowledge level of TB

patients, and to investigate the socio-demographic facors associated with knowledge level.

\section{Background}

In this study, the World Health Organization's (WHO) standard definition of TB was followed. TB cases are

defined as individuals diagnosed with TB by a health worker or other medical practitioner who has decided to treat the patient with a full course of anti-TB treat ment. A pulmonary TB patient is defined as a patien who has TB, which refers to a disease involving the lung parenchyma. An extra-pulmonary TB patient is defined as a patient who has TB disease, but refers to TB of organs other than the lungs, e.g. pleura, lymph nodes, abdomen, genitourinary tract, skin, joints and bones, meninges, central nervous system, spine, kidneys, pericardium, intestines and peritoneum. A new case is defined by the Bangladesh National TB control program (NTP) as being a patient who had never received antiTB treatment or who had received it for less than month after diagnosis by the government or non-government medical providers. An old case is defined as a patient who has been declared cured but remains a TB patient or not cured after completing continuous phase.

\section{Materials and Methods}

\section{Study are}

A cross sectional study was conducted in Rajshahi City, Bangladesh. Bangladesh is administratively divided into seven divisions and Rajshahi is one of them. Rajshah is the third most populous division with more than 21 million people, accounting for almost 13 percent of the Country's total population. The study area is located in the eastern part of the country, and was selected randomly. The study was carried out in the six different healthcare centers located in the city, namely Rajshahi Medical Collage Hospital (RMCH), Tilottoma (Noudapara Branch), Tilottoma (Bulonpur Branch), Rajshah Chest Disease Hospital (CDH), Rajshahi Chest Disease Clinic (CDC) and Population Service and Training Centre (PSTC) (Figure 1). These study areas provide free TB treatment under the directly observed therapy (DOT) program, which aims to control TB. control program is a national program of the Directorate General of Health Services (DGHS) under the Mycobacterium Disease Control (MBDC) unit which is run through National TB Control Programme (NTP).

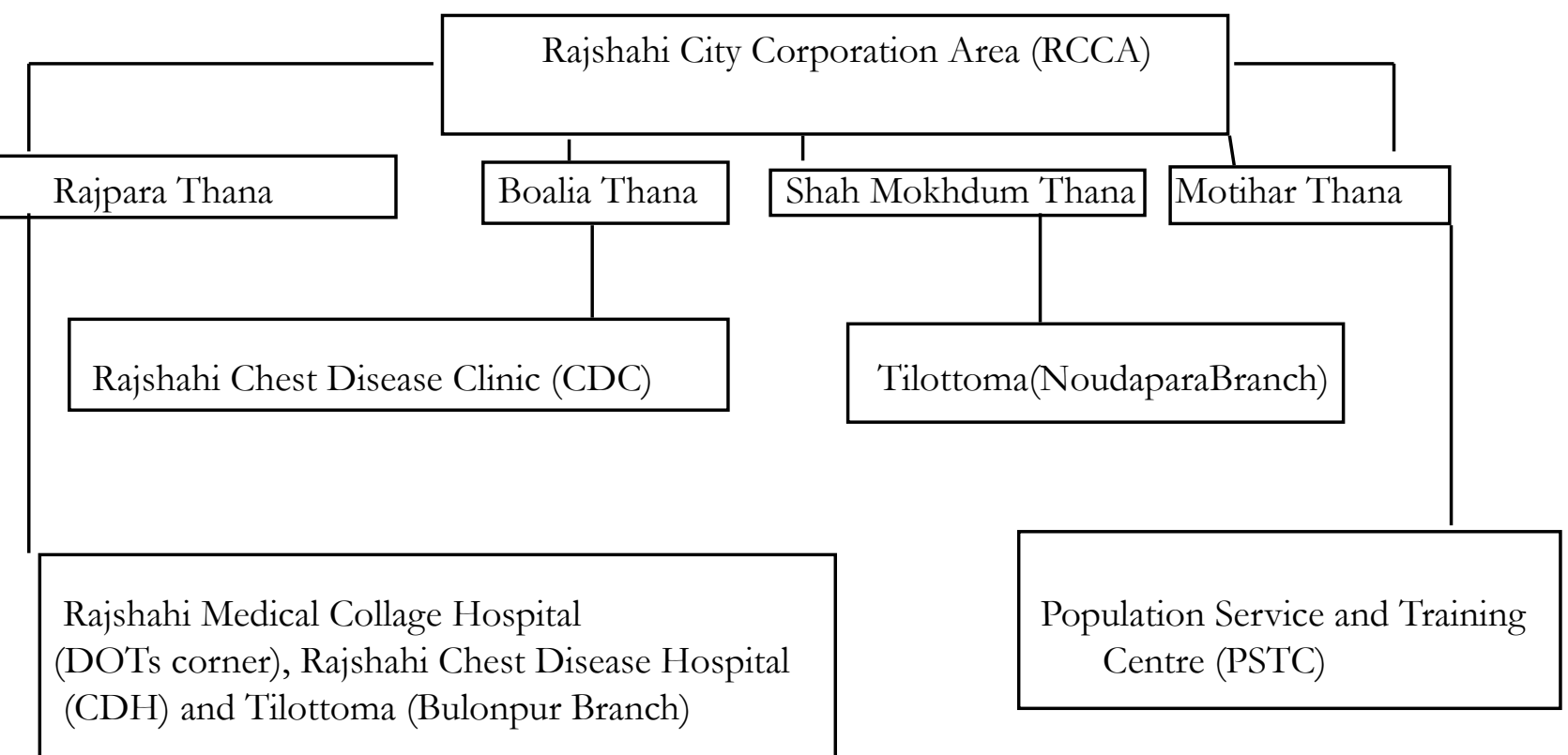

Respondents in this study include patients who began to Pulmonary sputum-positive TB was identified on the receive anti-TB treatment under DOT from June 2011 basis of at least 1 positive sputum culture of MTB or 2 to February 2012. Patients in whom TB is suspected are sputum smears containing acid fast bacilli in the context sent to the laboratory for sputum microscopy and are of a compatible clinical illness. Pulmonary sputumregistered in the TB laboratory register. Patients diag- negative TB was identified on the basis of negative nosed with smear-positive TB are registered for treat- smears and cultures for MTB in the context of cliniment in the TB treatment program. Smear-positive cally and radiologically compatible illness. Diagnosis pulmonary $\mathrm{TB}$ is diagnosed using direct sputum mi- of extra-pulmonary TB was based on a combination croscopy examination at the study areas, while smear- of clinical, radiological, and histopathological findings. negative pulmonary and extra-pulmonary TB is diag- For each patient, the following socio-demographic innosed by a graduate physician at hospital and respective formation was collected: sex, age, educational status; clinic. After diagnosis, most TB cases are treated and residence, delay in seeking treatment, TB type; and managed by study areas. The study population consist- knowledge regarding symptoms, transmission, treated of both pulmonary and extra-pulmonary $\mathrm{TB}$ cases, ment and prevention of TB.

and further divided into new and old cases, which are identified in the study sites by other diagnostic tools.

\section{Data Collection}

Three hundred and eighty four TB patients were interviewed face-to-face through a structured questionnaire using purposiv garding knowledge related to TB (Table1)and sociodemographic data(Table3) were collected from384 respondents. Two trained interviewers and a medical doctor conducted the interviews after obtaining informed consent at the study sites. Patients were informed clearly about the purpose of study. Both types of patients, pulmonary and extra-pulmonary were receiving treatment at the study sites.

\section{Data management and statistical analysis}

Data entry was performed using EPI info software and then was exported to the statistical package (SPSS 16.0) to analyze the data. Univariate analysis was completed to find the distributions of different dimensions of knowledge items and some selected sociodemographic characteristics. Indices of each of the four dimensions of knowledge concerning symptoms (DKS), transmission (DKT), treatment (DKTr), and prevention (DKP) were constructed using the sums of weighted binary input variables where maximum and minimum values were chosen for each underlying

dimension. Performance in each dimension is expressed as a unit-free index between 0 and 1 in accordance with 
the construction method of the Human development Index ${ }^{13}$ using the following equation:

Dimension Index $(\mathrm{DI})=$ Actual value - Minimum value Maximum value - Minimum value

Based on the above equation, dimension scores for symptoms were computed as follows;

Dimension Index for Symptoms (DIKS) = $\frac{\text { Actual value of symptoms - Minimum value of symptoms }}{\text { Maximum value of symptoms- }}$

Scores for each of the indices were averaged in order to compute the overall knowledge index

$(\mathrm{OKI})$ recorded as:

\section{OKI $=$ DIKS + DIKT + DIKTr + DIKP}

The scores obtained for this index were then transformed into a dichotomous variable with categories labeled low/moderate knowledge and sufficient knowl edge. Cronbach's $\alpha$ coefficient was used to evaluate the internal reliability of the OKI. The calculated value of $\alpha 0.785$, suggesting good internal consistency. The Pearson's Chi-squared $\left(\gamma^{2}\right)$ test was used to determine associations between OKI and socio-demographic predictors. Logistic regression analysis was used to determine the effects of selected socio-demographic predictors on knowledge level.

\section{Explanatory Variables}

The dependent variable in our analysis is the knowl edge level of the TB patients. The knowledge related variables were composed of four items. These items include knowledge about symptoms, knowledge about transmission, knowledge about treatment, and knowledge about prevention. Knowledge about symptoms includes, coughing with and without blood more than 3 weeks, chest pain; shortness of breath, loss of appetite, weight loss and fever with night sweating. Knowledge about transmission includes, understanding whether TB is communicable through sneezing, through air and through touching items from affected people. Knowledge about treatment includes un- derstanding that treatment is available, is treatment free, can regular intake of medicine cure a patient and does irregular intake of medicine cause death. Knowledge about prevention includes understanding that vaccine is available, stay far away from affected people when they sneeze, do not use items from affected people and always stay clean. The categories of the aforesaid questions are shown in Table 1. The dependent variable, knowledge level, in this study was categorized in two groups: low/moderate knowledge and sufficient knowledge. The dependent variable is considered for logistic regression model is coded in the following way:

$y=\{1$, is the knowledge level sufficient;

0 , otherwise.

A number of socio-demographic variables were included as independent variables. These variables include age, sex, educational status, place of residence, patient's delay and types of TB.

\section{Results}

A total of 384 TB patients participated in this study225(58.6\%) males and 159(41.4\%) females. Table 1 explains the four dimensions regarding the knowledge of TB. The majority of patients had knowledge about the symptoms of TB. The most frequently reported knowledge of symptoms was related to coughing $(97.9 \%)$, followed by chest pain $(60.2 \%)$, shortness of breath $(24.2 \%)$, loss of appetite $(50.8 \%)$, weight loss $(56.8 \%)$ and fever with night sweating $(70.6 \%)$. Most of the respondents were aware of the transmission routes of TB. Almost all (94.0\%) respondents knew TB is transmitted through sneezing and $89.8 \%$ respondents were aware that TB is communicable. Most of the patients were found to have good knowledge about treatment of TB. Essentially all of the respondents $(99 \%)$ were knowledgeable that treatment is available, $95.1 \%$ of respondents understood treatment is free and $97.1 \%$ believed regular intake of medicine can cure them. Close to half of the respondents $(48.4 \%)$ claimed that irregular intake of medicine can cause death. Almost all of the respondents $(98.4 \%)$ knew staying fat away from TB affected people was one of the fundamental preventive measures. Almost one third of respondents $(30.7 \%)$ had unsatisfactory knowledge about the vaccination for $\mathrm{TB}$

Table 1. Distribution of knowledge related variables and their categories

\begin{tabular}{|c|c|c|c|}
\hline \multirow{11}{*}{$\begin{array}{l}\text { Dimension of Knowledge } \\
\text { about Symptoms (DKS) }\end{array}$} & Explanatory variables & Categories & Frequency $(\%)$ \\
\hline & $\begin{array}{l}\text { Coughing with and without blood more than } 3 \\
\text { weeks }\end{array}$ & $\begin{array}{l}0=\text { No } \\
1=\text { Yes }\end{array}$ & $\begin{array}{c}8(2.1 \%) \\
376(97.9 \%)\end{array}$ \\
\hline & $\begin{array}{l}\text { weeks } \\
\text { Chest pain }\end{array}$ & $\frac{1-1 \mathrm{es}}{0=\text { No }}$ & $153(39.8 \%)$ \\
\hline & & $1=$ Yes & $231(60.2 \%)$ \\
\hline & Shortness of breath & & \\
\hline & & & \\
\hline & Loss of appetite & $0=$ No & $189(49.2 \%)$ \\
\hline & Weight loss & & $\frac{195(50.8 \%)}{166(43.2 \%)}$ \\
\hline & & $1=$ Yes & $218(56.8 \%)$ \\
\hline & Fiver with night sweating & $0=$ No & $113(29.4 \%)$ \\
\hline & & $1=$ Yes & $271(70.6 \%)$ \\
\hline \multirow{5}{*}{$\begin{array}{l}\text { Dimension of Knowledge } \\
\text { about Transmission (DKT) }\end{array}$} & Is TB communicable & $0=$ No & $39(10.2 \%)$ \\
\hline & Through sneezing & & \\
\hline & & $1=$ Yes & $361(94.0 \%)$ \\
\hline & Through air & $\begin{array}{l}0=\text { No } \\
1=\text { Yes }\end{array}$ & $129(33.6 \%)$ \\
\hline & Through using things of affected people & $0=\mathrm{No}$ & $203(52.9 \%)$ \\
\hline \multirow{6}{*}{$\begin{array}{l}\text { Dimension of Knowledge } \\
\text { about Treatment (DKTr) }\end{array}$} & Is treatment available & $0=$ No & $4(1.0 \%)$ \\
\hline & Is treatment free & $0=$ No & $19(4.9 \%)$ \\
\hline & & $1=$ Yes & $365(95.1 \%)$ \\
\hline & Is regular intake of medicine cure patient & $0=$ No & $11(2.9 \%)$ \\
\hline & Is irregular intake of medicine cause death/MDR & $\frac{1=\text { Yes }}{0=\text { No }}$ & $\frac{373(97.1 \%)}{198(51.6 \%)}$ \\
\hline & & $1=$ Yes & $186(48.4 \%)$ \\
\hline \multirow{7}{*}{$\begin{array}{l}\text { Dimension of Knowledge } \\
\text { about Prevention (DKP) }\end{array}$} & Is vaccine available & & \\
\hline & & $1=$ Yes & $118(30.7 \%)$ \\
\hline & Stay far away from affected people when sneeze & $0=$ No & $20(5.2 \%)$ \\
\hline & & $1=$ Yes & $364(94.8 \%)$ \\
\hline & Not use things of affected people & $0=$ No & $172(44.8 \%)$ \\
\hline & Get always clean & $\frac{1=\text { Yes }}{0=\text { No }}$ & $212\left(55.2^{2} \%\right)$ \\
\hline & & $\begin{array}{l}1=\text { Yes } \\
1=10\end{array}$ & $316(82.3 \%)$ \\
\hline & & & \\
\hline
\end{tabular}

The mean knowledge levels (MKL) are presented in Table 2. The pulmonary TB patients had a better knowl- patient's type, the patients recorded as old cases had edge level than the extra-pulmonary TB patients. The higher MKL for all of the dimensions as compared to mean OKI for pulmonary patients was 0.762 and for the new cases. The mean OKI for old cases was 0.763 and 0.701 of for new cases. 
Table 2. Distribution of mean knowledge by TB types and patient types

\begin{tabular}{|c|c|c|c|}
\hline \multirow{3}{*}{$\begin{array}{l}\text { Dimensions } \\
\text { Dimension of Knowledge about Symptoms } \\
\text { (DKS) }\end{array}$} & \multicolumn{2}{|c|}{ Types and categories of patients } & \multirow{2}{*}{$\begin{array}{l}\text { Mean } \\
0.363 \\
0.684 \\
\end{array}$} \\
\hline & Patient's type & $\begin{array}{l}\text { Extra-Pulmonary } \\
\text { Pulmonary }\end{array}$ & \\
\hline & Patient's Category & $\begin{array}{l}\text { New case } \\
\text { Old case }\end{array}$ & $\begin{array}{l}0.577 \\
0.704\end{array}$ \\
\hline \multirow{2}{*}{$\begin{array}{l}\text { Dimension of } \\
\text { Transmission (DKT) }\end{array}$} & Patient's type & $\begin{array}{l}\text { Extra-Pulmonary } \\
\text { Pulmonary }\end{array}$ & $\begin{array}{l}0.575 \\
0.802\end{array}$ \\
\hline & Patient's Category & $\begin{array}{l}\text { New case } \\
\text { Old case }\end{array}$ & $\begin{array}{l}0.731 \\
0.795\end{array}$ \\
\hline \multirow{2}{*}{$\begin{array}{l}\text { Dimension of Knowledge about Treatment } \\
\text { (DKTr) }\end{array}$} & Patient's type & $\begin{array}{l}\text { Extra-Pulmonary } \\
\text { Pulmonary }\end{array}$ & $\begin{array}{l}0.777 \\
0.874 \\
\end{array}$ \\
\hline & $\begin{array}{l}\text { Patient's Category } \\
\end{array}$ & $\begin{array}{l}\text { New case } \\
\text { Old case }\end{array}$ & $\begin{array}{l}0.837 \\
0.901\end{array}$ \\
\hline \multirow{2}{*}{$\begin{array}{l}\text { Dimension of Knowledge about Prevention } \\
\text { (DKP) }\end{array}$} & Patient's type & $\begin{array}{l}\text { Extra-Pulmonary } \\
\text { Pulmonary }\end{array}$ & $\begin{array}{l}0.575 \\
0.686\end{array}$ \\
\hline & Patient's Category & $\begin{array}{l}\text { New case } \\
\text { Old case }\end{array}$ & $\begin{array}{l}0.658 \\
0.651\end{array}$ \\
\hline \multirow{2}{*}{ Overall Knowledge Index (OKI) } & Patient's type & $\begin{array}{l}\text { Extra-Pulmonary } \\
\text { Pulmonary }\end{array}$ & $\begin{array}{l}0.572 \\
0.762 \\
\end{array}$ \\
\hline & Patient's Category & $\begin{array}{l}\text { New case } \\
\text { Old case }\end{array}$ & $\begin{array}{l}0.701 \\
0.763\end{array}$ \\
\hline
\end{tabular}

Table 3 illustrates patients' socio-demographic char- of respondents with sufficient knowledge was highacteristics affecting knowledge level. The study re- est among the most educated group, those with 12 o sults revealed that more than half $(61.8 \%)$ of all male more years of schooling $(68.5 \%)$. Most of the patient respondents, and half $(50.3 \%)$ of female respondents $(61.5 \%)$ lived in the urban area. More than three-fourth had sufficient knowledge about TB. The MKL was low- patients $(76.3 \%)$ were delayed in diagnosis of their TB er among females $(0.684)$ than of males $(0.732)$ and was status. Pulmonary patients were found to have a highe higher in ages 21-35 years old (0.774) as compared to percentage $(74.0 \%)$ among all patients, and most of other age groups. Moreover, respondents in the 21-35 them (70.8\%) had had sufficient knowledge. The $\chi^{2}$ year age group had the highest percentage with suffi- test results suggest that sex, age, educational status, and cient knowledge $(71.0 \%)$. Around half of the respond- TB type are significantly associated with the knowledge ents $(52.6 \%)$ were less educated, and the percentage level.

Table 3 Distribution of knowledge level according to different socio-demographic variables and

\begin{tabular}{|c|c|c|c|c|}
\hline \multirow[t]{2}{*}{ Explanatory variables } & \multirow{2}{*}{$\begin{array}{c}\text { Mean knowledge } \\
\text { level }\end{array}$} & \multicolumn{2}{|c|}{ Knowledge level } & \multirow[t]{2}{*}{ Total } \\
\hline & & Moderate knowledge & $\begin{array}{l}\text { Sufficient knowledge } \\
\end{array}$ & \\
\hline Sex** & & & & \\
\hline Male & 0.732 & $86(38.2 \%)$ & $139(61.8 \%)$ & $225(58.6 \%)$ \\
\hline Female & 0.684 & $79(49.7 \%)$ & $80(50.3 \%)$ & $159(41.4 \%)$ \\
\hline \multicolumn{5}{|l|}{ Age*** } \\
\hline$<20$ years & 0.674 & $25(59.5 \%)$ & $17(40.5 \%)$ & $42(10.9 \%)$ \\
\hline $21-35$ years & 0.774 & $40(29.0 \%)$ & $98(71.0 \%)$ & $138(35.9 \%)$ \\
\hline $36-50$ years & 0.702 & $57(46.7 \%)$ & $65(53.3 \%)$ & $122(31.8 \%)$ \\
\hline$>51$ years & 0.643 & $43(52.4 \%)$ & $39(47.6 \%)$ & $82(21.4 \%)$ \\
\hline \multicolumn{5}{|l|}{ Educational status** } \\
\hline $0-5$ years of schooling & 0.666 & $101(50.0 \%)$ & $101(50.0 \%)$ & $202(52.6 \%)$ \\
\hline 6-12 years of schooling & 0.760 & $47(36.7 \%)$ & $81(63.3 \%)$ & $128(33.3 \%)$ \\
\hline$>12$ years of schooling & 0.770 & $17(31.5 \%)$ & $37(68.5 \%)$ & $54(14.1 \%)$ \\
\hline \multicolumn{5}{|l|}{ Residence } \\
\hline Rural & 0.714 & $59(39.9 \%)$ & $89(60.1 \%)$ & \\
\hline & 0.711 & $106(44.9 \%)$ & $130(55.1 \%)$ & $236(61.5 \%)$ \\
\hline \multirow{2}{*}{$\begin{array}{l}\text { Patient's delay } \\
\text { No } \\
\text { Yos }\end{array}$} & 0.696 & $42(46.2 \%)$ & $49(53.8 \%)$ & $91(23.7 \%)$ \\
\hline & 0.717 & $123(42.0 \%)$ & $170(58.0 \%)$ & $293(76.3 \%)$ \\
\hline \multirow{4}{*}{$\begin{array}{l}\text { TB types*** } \\
\text { Extra-Pulmonary } \\
\text { Pulmonary }\end{array}$} & & & & \\
\hline & 0.572 & $82(82.0 \%)$ & $18(18.0 \%)$ & $100(26.0 \%)$ \\
\hline & 0.762 & $83(29.2 \%)$ & $201(70.8 \%)$ & $284(74.0 \%)$ \\
\hline & 0.712 & $165(43.0 \%)$ & $219(57.0 \%)$ & $384(100.0 \%)$ \\
\hline
\end{tabular}

Note: *** presents the significance level at $1 \%(\mathrm{p}<0.01), * *$ presents the significance level at $5 \%(\mathrm{p}<0.05)$ associations of knowledge level with such variables

Table 4 presents the results of the multivariate analysis Large, statistically significant differences in knowledge of the factors affecting knowledge level of the TB pa- level among TB patients were observed by educational tients. The results of the logistic regression suggest that level. Respondents with the highest level of education the socio-demographic variables selected for the analy- (12 years or more of schooling) were 8.097 times more sis are generally important predictors of knowledge likely to have sufficient knowledge compared to those level of the TB patients. Female TB patients were 0.824 who completed $0-5$ years of schooling. Urban respondtimes less likely to be informed compared to their male ents were 1.123 times more aware of TB compared to counterpart. Overall, age has a significant positive effect rural respondents. The patients with delayed diagnosis on knowledge level. The patients aged 21-35 years were were 0.89 time less likely to be informed. In case of 3.660 times more likely to have sufficient knowledge TB type of the patients, pulmonary TB patients were of TB than those who are 20 years of age or younger. 26.827 times more likely to be informed than extra-pulmonary TB patients.

Table 4. Affecting factors on knowledge level of the TB patients

\begin{tabular}{|c|c|c|c|c|c|}
\hline \multirow[t]{2}{*}{ Explanatory variables } & \multirow{2}{*}{ Betu $\left({ }^{\circ}\right)$ valoes } & \multirow{2}{*}{ SE of $f$} & \multirow{2}{*}{$\begin{array}{c}\text { Odd ratios } \\
\text { (OR) }\end{array}$} & \multicolumn{2}{|c|}{$95 \% \mathrm{CI}$} \\
\hline & & & & Upper leved & Lowet kvel \\
\hline \multicolumn{6}{|l|}{ Sex } \\
\hline $\begin{array}{l}\text { Mak (RO) } \\
\text { Fromak }\end{array}$ & 0.19 & 0273 & $\begin{array}{l}1.000 \\
0.824\end{array}$ & 0.482 & 1.07 \\
\hline \multicolumn{6}{|l|}{ Age } \\
\hline 20 years (RO) & & & 1000 & & \\
\hline 21.35 years & $1.297^{\mathbf{H}}$ & 0471 & 3.660 & 1.453 & 9.216 \\
\hline 3650 yars & 0570 & a 487 & $1.7 \theta$ & 0.681 & 4.598 \\
\hline$>51$ years & 0.410 & 0512 & 1507 & 0553 & 4.109 \\
\hline \multicolumn{6}{|l|}{ Educational status } \\
\hline 0.5 years of schooling $(\mathrm{RC})$ & & & 1000 & & \\
\hline 612 vears of schooling & $1.42 g^{2+3}$ & 0366 & 4.163 & 2032 & 8527 \\
\hline$>12$ years of shooting. & $2001^{1 \pi x}$ & 0519 & 8.097 & 2929 & 22382 \\
\hline \multicolumn{6}{|l|}{ Residence } \\
\hline $\operatorname{Rral}(\mathrm{RC})$ & & & 1000 & & \\
\hline Untan & 0.116 & a)s8 & 1.123 & 0.638 & 1.976 \\
\hline \multicolumn{6}{|l|}{ Patien?'s delay } \\
\hline No (RC) & & & 1.000 & & \\
\hline Yes & 0.117 & 0323 & 0.890 & $0.4 / 2$ & 1.675 \\
\hline \multicolumn{6}{|l|}{ TB types } \\
\hline Estra Pulmocary (RC) & & & 1000 & & \\
\hline Pulmonaly & $3.289+4$ & 0.91 & 26.827 & 12216 & 58915 \\
\hline Constans & -3497 & .705 & 0130 & & \\
\hline $2 \mathrm{Log}$ fikstibood & 384045 & & & & \\
\hline $\operatorname{Cox} \& \operatorname{Sax} \mathbb{R} R^{2}$ & 0.307 & & & & \\
\hline
\end{tabular}


The objective of this study was to determine the knowledge level of the TB patients and to what extent socio-demographic factors contribute to differences in knowledge level in Rajshahi city, Bangladesh. We collected and analyzed data from 384 TB patients who are diagnosed with TB and receiving anti-TB treatment. To our knowledge, no previous study has examined the

knowledge level in Rajshahi city, Bangladesh. The findings of this study suggest that more than $50 \%$ of the respondents knew about the symptoms of TB. Our findings suggest that socio-demographic variables played important roles on the knowledge level of the TB patients.

Logistic regression analysis showed age, educational status, and patient type were significantly associated with TB knowledge level. Patients in the 21-35 years of age group were significantly more likely to have sufficient knowledge about TB $(p<0.01)$ than those of $<20$ years of age group. Likewise, the patients who completed 6-12 years of schooling and $>12$ years of schooling were also significantly more likely to have sufficient knowledge status $(p<0.01)$ than those who completed 0-5 years of schooling. Hoa et. al. (2004) found similar results, which, consistent with our findings, highlighted educational level as an important determinant of people's level of knowledge of TB, and persons with a higher level of education scored bette on TB knowledge indices than those with less education or those who were illiterate. This study has shown that,while socio-demographic factors may not necessarily be causative factors to becoming infected with TB, they do significantly influence knowledge levels of TB patients.

The findings of this study are consistent with some other national studies. For example, one study conducted in Iraq found the similar result with around $50 \%$ of the patients had good knowledge about the symptoms of $\mathrm{TB}^{14}$. Another study conducted in Ndola, Zambia found that over $70 \%$ of TB patients had an idea about the symptoms, including fever with night sweating, weight loss, loss of appetite and coughing with and without blood for more than 3 weeks ${ }^{15}$. Coughing with and without blood for more than 3 weeks is regarded as a TB suspicious symptom and only 16\% people in Yangzhong County, a rural area
$97.9 \%$ patients knew coughing with and without blood for more than 3 weeks is one of the major symptoms of TB. Another study conducted in the north and central regions of Vietnam found coughing was the mos frequently mentioned symptom, and was reported by 298 patients $(81.9 \%)^{17}$. A similar result was found in Ibadan, Nigeria where a study conducted among pulmonary patients revealed more than $80 \%$ ofthe patients recognized coughing as major symptoms of $\mathrm{TB}^{18}$. Focused health education programs in Bangladesh appear to have made a great impact on the level of patient knowledge about TB.

Since TB is a contagious, communicable disease; i spreads through contact with an infected person, making the understanding of human transmission of infection absolutely critical to its control ${ }^{19}$. Around $95.3 \%$ of pulmonary patients in the north and central regions of Vietnam were aware that TB is a contagious disease ${ }^{20}$. From the current study, we find almost all patients have heard about TB and more than $89.8 \%$ knew it was a communicable disease, and almost all patients knew the treatment of TB is available, free, and regular intake of medicine can cure a patient. Nearly half of the patients had an idea that contact with infected people's belongings can spread TB. Our findings are consistent with several other studies which have investigated knowledge levels of TB in other countries ${ }^{14,16-18}$.

While overall knowledge levels are relatively high in Bangladesh, specific knowledge about TB associated with health-care seeking behaviors still appears unsatisfactory. Many people living with TB remain underreported because of lack of knowledge about treatment and the TB control program. Poor knowledge of TB patients concerning their disease may contribute to the high prevelance of TB disease in the country ${ }^{21}$. Our findings suggest that the mean level of knowledge was higher among pulmonary patients because mos of the symptoms, transmission, and prevention item listed in this study were related to the pulmonary patients. This fact highlighted the difference in knowledge level among pulmonary TB patients and other TB patients. The study also showed the mean knowledge level among the patients identified as new cases was lower than the patients recorded old cases Specifically, the mean OKI for new cases was 0.701 and for old cases was 0.763 . This result suggests that overall knowledge levels are relatively high for patients of both categories, and are similar to the Vietnam study, which showed patients in the north and middle of Vietnam had reasonably sufficient knowledge about $\mathrm{TB}^{18}$. However, several other studies have concluded that knowledge about TB among new pulmonary TB patients was quite low, which is contradicted in this study $y^{22,23}$.

A prior study conducted in Hyderabad, India found socio-demographic variables, which included age, sex, educational status, occupation, monthly income, nutritional status, addiction etc., are closely linked with TB prevalence and knowledge level ${ }^{18,24-25}$. In the present study, we found that age, sex, and educational status were variables that influence $\mathrm{TB}$ related knowledge. This result was similar to the study conducted among patients in Iraq, which highlighted age and educational status as being significant predictors of knowledge of $\mathrm{TB}^{16}$. In our study, a large number of patients seeking treatment at the study sites were males, of which knowledge level was high (0.732). A number of other studies have shown that, in developing countries, male TB patients account for two thirds of total reported TB patients $^{26}$. Globally, approximately $70 \%$ more males are notified of smear-positive TB tests than females ${ }^{27}$. According to $\mathrm{WHO}$, the prevalence of $\mathrm{TB}$ is more common among men than women ${ }^{28}$. Ahsan et al. found that female patients are mostly illiterate and live in poo socio-economic conditions. It is quite apparent that socio-economic and cultural factors, are important determinants of gender differentials in TB prevalence ${ }^{20}$ Females are often unable to reach health facilities because a woman's position in the household, economic dependence, and illiteracy would be restricting factors

Aside from gender differences, our study also revealed that most of the TB patients seeking treatment belonged to the 21-35 years of age group, and that the MKL (0.774) was higher for this age group. Additional- $y$, higher MKL was found among the patients completing $>12$ years of schooling. These results suggest that age and education level are important determinants of general knowledge of TB, and this finding is also consistent with other studies ${ }^{18,23}$. It should also be noted, however, that this study has some limitations. It is based on a cross sectional data and sample size is small. The population consists of Rajshahi city and not of Bangladesh as an entire country. Given the limitations of the present study, future studies should consider larger sample, especially, nationally representative sample.

\section{Conclusion}

Knowledge level among the TB patients in Rajshahi city is relatively high, yet it was dependent on some sociodemographic factors. Males were better informed than females, and the young adult population, ages 21-35, was more aware about $\mathrm{TB}$ transmission routes and preventative measures. Also, more highly educated and urban area patients were comparatively well informed about TB infection. Patients with greater knowledge about TB were also less likely to be delayed in seeking diagnosis of their TB status. Strengthening awareness of TB and improving the accessibility of healthcare services is essential in TB control strategies, especially under he current vertical TB control system.

\section{Ethical consideration}

Ethical issues (Including plagiarism, Informed Consent, misconduct, data fabrication and/or falsification, double publication and/or submission, redundancy, etc.) have been completely observed by the authors.

\section{Acknowledgements}

The authors are very grateful to the Department of Population Science and Human Resource Development, University of Rajshahi, Bangladesh by giving an opportunity to complete this study fruitfully. Author are very grateful to the respondents as well as the authority of the TB centers. Thanks are also due to the editor and reviewers of the Journal of African Health Sciences for their valuable comments and criticisms, which led to a greatly improved revision of this paper. 
1. Gupta RK, Gupta A, Jamwal DS, et al. A Socio-Epidemiological Study of Tuberculosis in a Rural Area. JK Science, 2002; 4(3):119-122.

2. WHO. Global Tuberculosis Control.' World Healt Organization (WHO), Zeneva, 2011.

3. Mondal MNI, Shitan M. Relative Importance of Factors on Life Expectancy in the Low and Lower Middle Income Countries. Journal of Epidemiology, 2014; 24(2): $117-124$

15. Hashim DS, Kubaisy WA and Dulayme AA Knowl-

edge, Attitudes and Practices Survey among Health Care Workers and Tuberculosis Patients in Irac Eastern Mediterranean Health Journal, 2003; 9(4):718-731. 16. Kaona FAD, Tuba M, Siziya S, et al. An Assessment of Factors Contributing to Treatment Adherence and Knowledge of TB Transmission among Patients on TB Treatment. BMC Public Health, 2004 4:68

. Mondal MNI, Shitan M. Impact of Socio-Healt Factors on Life Expectancy in the Low and Lower Mid- Knowledge about Tuberculosis and its Treatmen dle Income Countries. Iranian Journal of Public Health, among New Pulmonary TB Patients in the North and 2013; 42(12):1354- 62

5. Mondal MNI, Shitan M. Factors Affecting the 8(5):603-608

HIV/AIDS Epidemic: An Ecological Analysis of 18. Fatiregun AA, and Ejeckam CC. Determinants of Global Data. African Health Sciences, 2013; 13(2): 294- Patients Delay in Seeking Treatment among Pulmonar 303.

6. Ullah ANZ, Newell JN, Ahmed JU, et al GovernmentNGO Collaboration: the Case of Tuberculosis Control in Bangladesh. Health Policy Plan, 2006; 21(2):143-155. 7. Koay TK. Knowledge and Attitudes towards Tuberculosis among the People Living in Kudat District, $\mathrm{Sa}$ bah. Med J Malaysia, 2004; 59(4):502-511.

8. Karim F, Islam MA, Chowdhury AM, et al. Gende Differences in Delays in Diagnosis and Treatment of Tuberculosis. Health policy and planning, 2007; 22(5):329334.

9. Ngadaya ES, Mfinanga GS, Wandwalo E, et al. Delay in Tuberculosis Case Detection in Pwani region, Tanzania: A Cross-sectional Study. BMC Health Services Research, 2009; 9:196.

10. Long Q, Li Y, Wang Y, et al. Barriers to Accessing TB Diagnosis for Rural-to-Urban Migrants with Chronic Cough in Chongqing, China: A Mixed Methods Study. BMC Health Services Research, 2008; 8:202. 11. Demissie M, Lindtjorn B, and Berhane Y. Patient and Health Service Delay in the Diagnosis of Pulmonary Tuberculosis in Ethiopia. BMC Public Health, 2002; 2:23.

12. Mauch V, Woods N, Kirubi B, et al. Assessing Access Barriers to Tuberculosis Care with the Tool to Estimate Patients' Costs: Pilot Results from two Districts in Kenya. BMC Public Health, 2011; 11:43.

13. UNDP. Human development Report 2011. United

Nations Development Program (UNDP), 2011, New York, USA.

14. Wang J, Fei Y, Shen H, et al. Gender Difference in Seeking Behavior in a Rural Area of Nepal. Int J Tuber Knowledge of Tuberculosis and Associated Health- Lung Dis, 2001; 5(1):24-31.

care Seeking Behaviors: A Cross-sectional Study in a 27. Diwan VK, and Thorson A. Sex, Gender, and Tu28. Neyrolles $\mathrm{O}$, and Quintana ML. Sexual Inequality in Tuberculosis. Plos Med, 2009; 6(12):e1000199.
29. Kaulagekar A, and Radkar A. Social Status Makes (n) Family Health Survey-2. Indian I Tuberc, 2007; 54:17-23. 